\title{
Synthesis, characterization and catalytic activity of nanosized Ni complexed aminoclay
}

\author{
A. Amala Jeya Ranchani ${ }^{1} \cdot$ V. Parthasarathy ${ }^{1}$ - A. Anitha Devi ${ }^{2}$ B. Meenarathi ${ }^{2}$. \\ R. Anbarasan ${ }^{3}$
}

Received: 23 June 2017/ Accepted: 11 September 2017/Published online: 19 September 2017

(c) The Author(s) 2017. This article is an open access publication

\begin{abstract}
A novel Ni complexed aminoclay (AC) catalyst was prepared by complexation method followed by reduction reaction. Various analytical techniques such as FTIR spectroscopy, UV-visible spectroscopy, DSC, TGA, SEM, HRTEM, EDX, XPS and WCA measurement are used to characterize the synthesized material. The AC-Ni catalyst system exhibited improved thermal stability and fiber-like morphology. The XPS results declared the formation of Ni nanoparticles. Thus, synthesized catalyst was tested towards the Schiff base formation reaction between various bio-medical polymers and aniline under air atmosphere at $85{ }^{\circ} \mathrm{C}$ for $24 \mathrm{~h}$. The catalytic activity of the catalyst was studied by varying the \% weight loading of the AC-Ni system towards the Schiff base formation. The Schiff base formation was quantitatively calculated by the ${ }^{1} \mathrm{H}$-NMR spectroscopy. While increasing the \% weight loading of the AC-Ni catalyst, the \% yield of Schiff base was also increased. The $k_{\text {app }}$ and Ti values were determined for the reduction of indole and $\alpha$-terpineol in the presence
\end{abstract}

Electronic supplementary material The online version of this article (doi:10.1007/s13204-017-0595-6) contains supplementary material, which is available to authorized users.

R. Anbarasan

anbu_may3@yahoo.co.in

1 Department of Physics, Hindustan University, Padur, Chennai, Tamil Nadu 603 103, India

2 Department of Polymer Technology, Kamaraj College of Engineering and Technology, Virudhunagar, Tamil Nadu 626001 , India

3 Department of Chemical Engineering, National Taiwan University, Taipei 10617, Taiwan, ROC of AC-Ni catalyst system. The experimental results were compared with the literature report.

Keywords Aminoclay-Ni catalyst - Synthesis and characterization · Schiff base $\cdot{ }^{1} \mathrm{H}-\mathrm{NMR}$ spectroscopy Catalytic reduction

\section{Introduction}

Recently, the material chemists turned their attention towards the synthesis, characterization and applications of nanomaterials. Among the nanomaterials, clay plays a vital role in various science and engineering fields (Suresh et al. 2017) because of its availability in excess, low cost and its excellent catalytic activity (Zhu et al. 2001; Duraimurugan et al. 2008). Aminoclay (AC) is a water soluble synthetic phyllosilicate clay material with free amino groups. In biomedical engineering, the $\mathrm{Fe}-\mathrm{AC}$ is used for harvesting microalga (Lee et al. 2014) drug delivery carrier (Yang et al. 2014) and bio-imaging (Kang et al. 2015). In 2007, Datta et al. (2007) reported the metal nanoparticle embedded AC catalyzed reduction of nitrophenol. Arvaniti et al. (2015) studied on the reduction and degradation of perfluorinated compound with zero valent iron decorated AC. Fe-AC catalyzed decoloration of azo dyes in the presence of $\mathrm{H}_{2} \mathrm{O}_{2}$ was reported by Lee and research team (Lee et al. 2013). Flurbiprofen encapsulated AC for the effective drug delivery was reported in the literature (Yang et al. 2013). Pd embedded AC was used for the deoxygenation of strearic acid (Giardono et al. 2016). Fe-AC entrapped poly(acrylonitrile) nanofiber was used for the decolorization of methylene blue dye (Lee et al. 2015). Au nanoparticle was prepared in the presence of AC by Burkett et al. (1997). Biomolecule wrapped AC was reported 
by Patil et al. (2004). The Ag-Au bimetallic nanoparticle decorated AC catalyzed reduction of nitrophenol was reported in the year 2015 (Ravula et al. 2015). Reductive decontamination of nitrophenol was done with the aid of $\mathrm{Mg}-\mathrm{AC}$ (Hwang et al. 2014). Other authors (Vandarkuzhali and Radha 2013; Liu et al. 2016; Celebi et al. 2016) also reported about the catalytic activity of metal nanoparticle immobilized AC. By thorough literature survey, it was found that the catalyst was deactivated fast due to leach of metal nanoparticles into the reaction medium in the subsequent runs and hence it leads to the low $\%$ of aimed product. Sometimes, the catalytic reaction requires expensive instruments. Hence, it is necessary to design a chemical route to outwit the problems mentioned above in an economic way without using any hazardous solvents. Moreover, the catalyst should be a compatible one. This urged to do the present investigation in an eco friendly manner.

Nickelsulphate is water soluble, colored, complex forming (Wang et al. 2016; Rosetto et al. 2015) and economically cheaper material with catalytic activity (Liu et al. 2009; Franquin et al. 1999). Catalytic hydrogenation of imines using Ni catalyst was reported by Ayyala et al. (2004). While going through the literature, any report based on $\mathrm{AC}$ and $\mathrm{Ni}^{2+}$ could not be found. Both $\mathrm{AC}$ and nickel sulphate are water soluble and can easily form complex.

Recently, the polymer chemists are doing active research on the structural modification of bio-medically important polymers. Among the bio-medical polymers, poly(ethyleneglycol) (PEG) (Li and Kao 2003), poly( $\varepsilon^{-}$ caprolactone) (PCL) (Meenarathi et al. 2016) and chitosan (Chit) (Haldoraj et al. 2015) are playing vital role in biomedical engineering field. This is because of their biocompatibility, bio-degradability, ease of synthesis and low cost with less cytotoxicity (Alcanter et al. 2000). Unfortunately, their applications are restricted due to the reasons listed below: the high moisture adsorption (except PCL) leads to reduction in their mechanical properties, susceptible to attack by air living microbial systems that leads to chain degradation, resulting in decrease in molecular weight. Aerial oxidation leads to brown and hence reduction in the quality of the material. The above said problems can be outwitted in a single step reaction without using any hazardous solvents (i.e.) structural modification with aniline leads to Schiff base formation. The Schiff base formation offers antimicrobial activity and rigidity to biomedical polymer without any degradation. Generally, a Schiff base is synthesized by treating an aldehyde with a primary amine. Generally, such a Schiff base formation occurred in a two-step reaction (i.e.) oxidation of primary alcohol into aldehyde in the presence of catalyst followed by Schiff base formation with aniline. In the present investigation, such a two-step reaction is modified into a single step reaction in an economically cheaper way. This is the novelty of the present investigation. Various catalyst systems were used for the preparation of Schiff base from primary alcohol and amine such as: Ironoxide supported mesoporous carbon (Geng et al. 2016), $\mathrm{Au} / \mathrm{ZrO}{ }_{2}$ (Cui et al. 2013), $\mathrm{CeO}_{2}$ (Tamura and Tomishige 2014), Ruthenium $\mathrm{N}$-heterocyclic carbene complex (Maggi and Madsen 2012), $\mathrm{Fe}\left(\mathrm{NO}_{3}\right.$ ) (Zhang et al. 2013), $\mathrm{Pd} / \mathrm{AlO}(\mathrm{OH})$ (Kwon et al. 2009), Vanadium (Wang et al. 2015), Cobalt complex (Zhang and Hanson 2013) and Ru pincer complex (Sindhuja and Ramesh 2014). By thorough literature survey, AC-Ni system catalyzed synthesis of Schiff base particularly with the macromolecular systems could not be found. For the first time, the macromolecular Schiff base was synthesized in a novel methodology in the presence of AC$\mathrm{Ni}$ system as a catalyst under air atmosphere.

$\alpha$-Terpineol is originated from the pine smoke with pleasant odor and is widely used in the perfume and cosmetic industry. Terpineol is usually a mixture of isomers with $\alpha$-terpineol as the major constituent. $\alpha$-terpineol and its isomers when mixed with water beyond certain limit, the quality of water is disturbed particularly the color and $\mathrm{pH}$ of water and hence unfit the domestic application. So that it is necessary to find out a way to reduce the pollution due to terpineols. The literature indicates that catalytic reduction is a simple single step procedure to reduce the pollution and isolate the reduced product. In 1963, von Rudloff (1963) studied about the reduction of $\alpha$-terpineol using Pd and Pt catalyst. Behal used Ni catalyst for the reduction of $\alpha$-terpineol (Behal 1910). Wallach used colloidal Pd catalyst for the reduction of $\alpha$-terpineol (Wallach 1911). On going through the literature, we could not found any report based on $\mathrm{AC}-\mathrm{Ni}$ catalyzed reduction of $\alpha$ terpineol.

Indole is an aromatic nitrogen containing heterocyclic organic compound with bicyclic structure and is solid at room temperature. Indole and its derivatives have unpleasant smell and they are highly toxic and carcinogenic. Hence, it is necessary to reduce or arrest the toxicity in an economic way. Catalytic reduction is a simple way to reduce the toxicity of indole by reducing its structure. In 2011, Kulkarni et al. (2011) reported the Pt/C catalyzed reduction of indole in an aqueous medium. Rh complex catalyzed reduction of indole was reported in the literature (Kuwano et al. 2006). Similarly, other catalysts such as Pd/ $\mathrm{C}$ (Deng et al. 2015) and $\mathrm{LiAlH}_{4}$ (Leete and Marion 1953) were used for the reduction of indoles. The literature survey indicates that the $\mathrm{AC}-\mathrm{Ni}$ catalyst system has not used for the reduction of indole. This urged us to do the present investigation. 


\section{Experimental}

\section{Materials}

3-Aminopropyltrimethoxysilane (APTMS) was purchased from Sigma Aldrich, India and used as received. Magnesium nitrate was purchased from Merck, India. Nickel sulphate, sodiumlauryl sulphate (SLS) and aniline (ANI) were purchased from S.D fine chemicals, India. Ethanol was purchased from $\mathrm{CDH}$, India. Double distilled water (DDW) was used for washing and solution preparation. Diethylether, tetrahydrofuran (THF) and aceticacid were purchased from Spectrum chemicals, India. The thymol blue end capped poly( $\varepsilon$-caprolactone) (PCL, $M_{\mathrm{w}}=3840 \mathrm{~g} / \mathrm{mol}$ ) is a gift sample from our own research team.

\section{Synthesis of AC and AC-Ni catalyst system}

To prepare AC, a standard literature procedure was followed (Datta et al. 2007). $4.2 \mathrm{~g} \mathrm{MgNO}_{3}$ was added with $100 \mathrm{~mL}$ ethanol under stirring at room temperature. With this $3.8 \mathrm{~mL}$ of APTMS was added under stirring and the mixing continued for $5 \mathrm{~h}$. The resulted white slurry was isolated by centrifugation for $5 \mathrm{~min}$. The supernatant liquid was discarded and the precipitate was further centrifuged with $10 \mathrm{~mL}$ of ethanol. The centrifugation was repeated for 3-4 times to remove the unreacted reactants and other impurities. Finally, the precipitate was dried at $60{ }^{\circ} \mathrm{C}$ for $6 \mathrm{~h}$, ground, weighed and stored in zipper lock cover. Thus, obtained white powder is called as aminoclay (AC) which is completely soluble in water.

One $\mathrm{g}$ AC was dissolved in $50 \mathrm{~mL}$ DDW. With this $0.50 \mathrm{~g}$ nickelsulphate was added and stirred for $2 \mathrm{~h}$ at room temperature. During the stirring process, the $\mathrm{Ni}^{2+}$ ions were complexes with the amino group of AC (Hwang et al. 2014). The changing color of reaction medium (i.e.) conversion of dark green color into a pale green color confirmed the complex formation. After the complexation process, $0.025 \mathrm{~g}$ of $\mathrm{NaBH}_{4}$ was weighed accurately and mixed with the solution under mild stirring condition. The reduction of $\mathrm{Ni}^{2+}$ into $\mathrm{Ni}^{0}$ was confirmed by a change in color to a dark black. The reduction reaction was continued for another $2 \mathrm{~h}$ under stirring. The contents were treated with $50 \mathrm{~mL}$ ethanol and centrifuged for $5 \mathrm{~min}$. The supernatant liquid had unreacted Nickelsulphate and physically formed $\mathrm{Ni}$ nanoparticles were removed. The centrifugation was repeated for 3-4 times to remove the impurities completely. To confirm, the supernatant liquid was subjected to UV-visible spectrum measurement. The washing process continued until the disappearance of peak around $200-500 \mathrm{~nm}$. The black colored precipitate was dried at $60{ }^{\circ} \mathrm{C}$ for $6 \mathrm{~h}$, ground, weighed and stored in a zipper lock cover. Thus, obtained product is named as AC$\mathrm{Ni}$ catalyst system.

\section{Synthesis of PCL based Schiff base}

$0.50 \mathrm{~g}$ PCL sample was dissolved in $100 \mathrm{~mL}$ THF solvent at $60{ }^{\circ} \mathrm{C}$ for $10 \mathrm{~min}$. Then, $2 \mathrm{~mL}$ of ANI and $3 \%$ weight of AC-Ni catalyst were added under vigorous stirring condition. The stirring was continued for $24 \mathrm{~h}$. The molecular oxygen is acting as an oxygen source material (Wang et al. 2015). Once the color of the medium is slightly changed into pale yellow, the reaction was stopped and dried. The dried mass was washed with acetone for 2-3 times to remove the unreacted ANI, weighed and stored in a zipper lock cover. The $\%$ Schiff base formation was determined from the ${ }^{1} \mathrm{H}-\mathrm{NMR}$ spectroscopy as $33 \%$ using Eq. (1). The Schiff base formation reaction is given in Scheme 1.

$\%$ yield of Schiff base $=\frac{A_{\frac{8.2}{1}}}{A_{\frac{3.6}{2}}} \times 100$

\section{Catalytic reduction of indole and $\alpha$-terpineol}

The catalytic reduction of indole or $\alpha$-terpineol was carried out by following a standard literature procedure (Biswas and Jackson 1968). The catalytic reduction study was quantitatively carried out with the help of UV-visible spectrophotometer. $1.25 \times 10^{-5} \mathrm{M}$ solution of indole or $\alpha$ terpineol was prepared in a $10 \mathrm{~mL}$ standard measuring flask (SMF). From the SMF, $2 \mathrm{~mL}$ solution was pipette out into a $3 \mathrm{~mL}$ capacity quartz cuvette followed by the

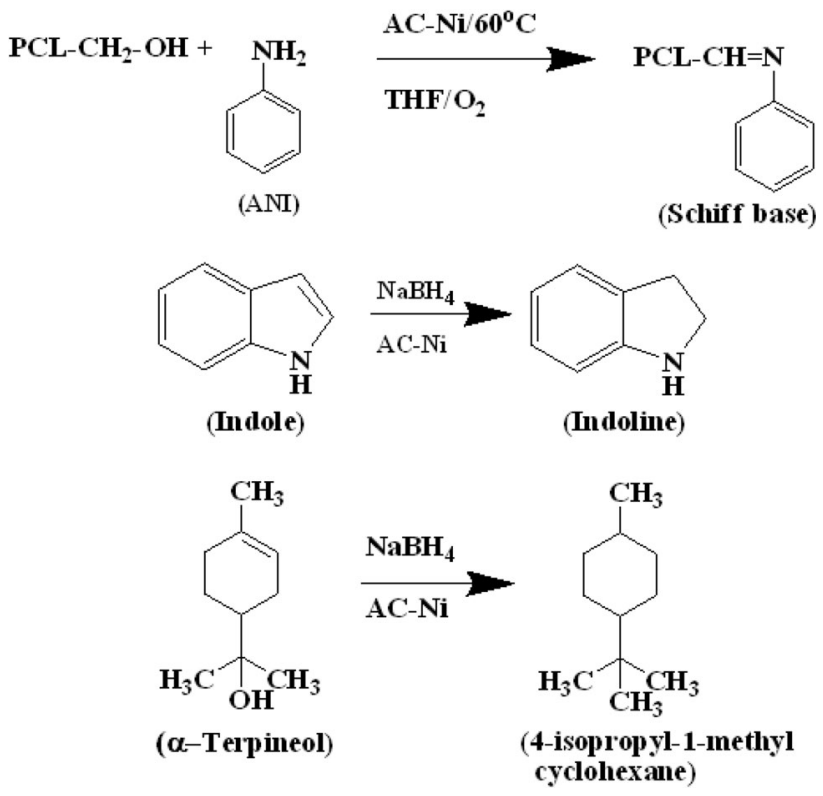

Scheme 1 Catalytic activity of AC-Ni system 
addition of $1 \mathrm{mg}$ of AC-Ni catalyst and $15 \mathrm{mg}$ (in excess quantity) of $\mathrm{NaBH}_{4}$ (a reducing agent). The cuvette was shaken well for a second and subjected to UV-visible spectral measurement. The spectrum was taken for $1 \mathrm{~min}$ time interval. From the absorbance value, the $k_{\text {app }}$ and $\mathrm{Ti}$ values were calculated. The reaction is given in Scheme 1 .

\section{Measurements}

The chemical structure of PCL-Schiff base was confirmed by ${ }^{1} \mathrm{H}-\mathrm{NMR}$ spectroscopy (Bruker $300 \mathrm{MHz}$ in $\mathrm{CDCl}_{3}$ solvent). Fourier transform infrared (FTIR) spectra for the samples were recorded with the help of a Shimadzu $8400 \mathrm{~S}$, Japan instrument by $\mathrm{KBr}$ pelletization method from 400 to $4000 \mathrm{~cm}^{-1}$. The UV-visible spectrum was measured using Shimadzu 3600 NIR spectrophotometer, Japan. Water contact angle (WCA) was measured using Kyowa DMs200, Japan model instrument. Differential scanning calorimetry (DSC) and thermo gravimetric analysis (TGA) were measured using Universal V4.4A TA Instruments under nitrogen atmosphere at the heating rate of $10{ }^{\circ} \mathrm{C}$ $\mathrm{min}^{-1}$ from room temperature to $800{ }^{\circ} \mathrm{C}$. High resolution transmission electron microscopy (HRTEM) image was recorded using TEM 3010 instrument, a product of JEOL. The surface morphology of the samples was scanned using High resolution scanning electron microscopy (HRSEM, JSM 6300, JEOL model, USA) instrument. The binding energy was determined by XPS (XPS, Thermo Scientific, Theta Probe, UK).

\section{Results and discussion}

\section{Characterization of AC-Ni catalyst}

\section{FTIR spectroscopy}

$\mathrm{AC}$ and its Nickel complex are characterized by various analytical techniques. The functional groups present are characterized by FTIR spectroscopy. Figure 1a indicates the FTIR spectrum of AC. A broad peak around $3432 \mathrm{~cm}^{-1}$ is due to $\mathrm{O}-\mathrm{H}$ stretching (Jeyapriya et al. 2016). A twin peak at 2937 and $3048 \mathrm{~cm}^{-1}$ are corresponding to the free $-\mathrm{NH}_{2}$ stretching. This confirmed the availability of free amino group at the end of the propyl group. The bending vibration of $\mathrm{O}-\mathrm{H}$ appeared at $1625 \mathrm{~cm}^{-1}$. The $\mathrm{C}-\mathrm{H}$ bending observed at $1504 \mathrm{~cm}^{-1}$. The $\mathrm{C}-\mathrm{N}$ stretching observed at $1395 \mathrm{~cm}^{-1}$. The $\mathrm{Si}-\mathrm{O}-\mathrm{Si}$ stretching appeared at $1008 \mathrm{~cm}^{-1}$. The $\mathrm{Si}-\mathrm{O}$ stretching appeared at $560 \mathrm{~cm}^{-1}$. The FTIR spectrum of AC-Ni complex system is given in Fig. $1 \mathrm{~b}$ with the appearance of peaks corresponding to the AC. Apart from those, some new peaks were also seen. The $\mathrm{C}-\mathrm{H}$ stretching was noticed at $2876 \mathrm{~cm}^{-1}$. A shift in the

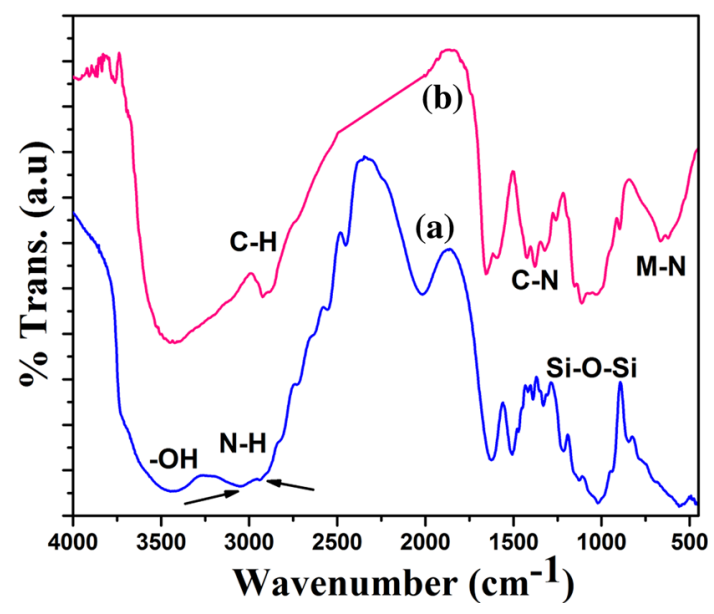

Fig. 1 FTIR spectrum of a AC and b AC-Ni system

$\mathrm{C}-\mathrm{N}$ stretching and $\mathrm{O}-\mathrm{H}$ bending vibration is associated with the Nickel complex formation with AC. The metalnitrogen stretching $\left(661 \mathrm{~cm}^{-1}\right)$ appeared clearly after the complex formation (i.e.) the amino group of $\mathrm{AC}$ with the central $\mathrm{Ni}^{2+}$ ions. Thus, the appearance of new peaks and shifting in the peak position (Jeyapriya et al. 2016) confirmed the Nickel complex formation with AC.

\section{UV-visible spectroscopy}

The electronic transition present in the material can be determined by UV-visible spectroscopy. Figure 2a confirms the UV-visible spectrum of pristine AC. There is no absorption peak. Figure $2 \mathrm{~b}$ represents the UV-visible spectrum of AC-Ni system. The UV-visible spectrum of AC-Cu system was studied by Datta et al. (2013). Ramya et al. (2015) reported the UV-visible spectrum of AC. The result co-insides with their report. $\mathrm{As}_{\mathrm{SiO}_{2}}$ is a semiconductor and the energy band gap of Si found before and after complexation reaction with the help of Tauc's plot. Figure $2 \mathrm{c}$ represents the Tauc's plot for AC system and the $E_{\mathrm{g}}$ value is $5.91 \mathrm{eV}$. Figure $2 \mathrm{~d}$ indicates the Tauc's plot for $\mathrm{AC}-\mathrm{Ni}$ complex system. The present system yielded the $E_{\mathrm{g}}$ value of $3.92 \mathrm{eV}$ after the complex formation with $\mathrm{Ni}$, the $E_{\mathrm{g}}$ value reduced drastically. The band gap energy was reduced via complexation reaction and this increases the application of such an AC-Ni system in various semiconductor and electrical engineering field.

\section{DSC analysis}

The thermal transition in the AC before and after the complexation process is determined by DSC technique. The DSC thermogram of pristine AC is given in Fig. S1a. It exhibits an endothermic peak at $153{ }^{\circ} \mathrm{C}$ corresponding to the removal of chemisorbed water molecules, represented 

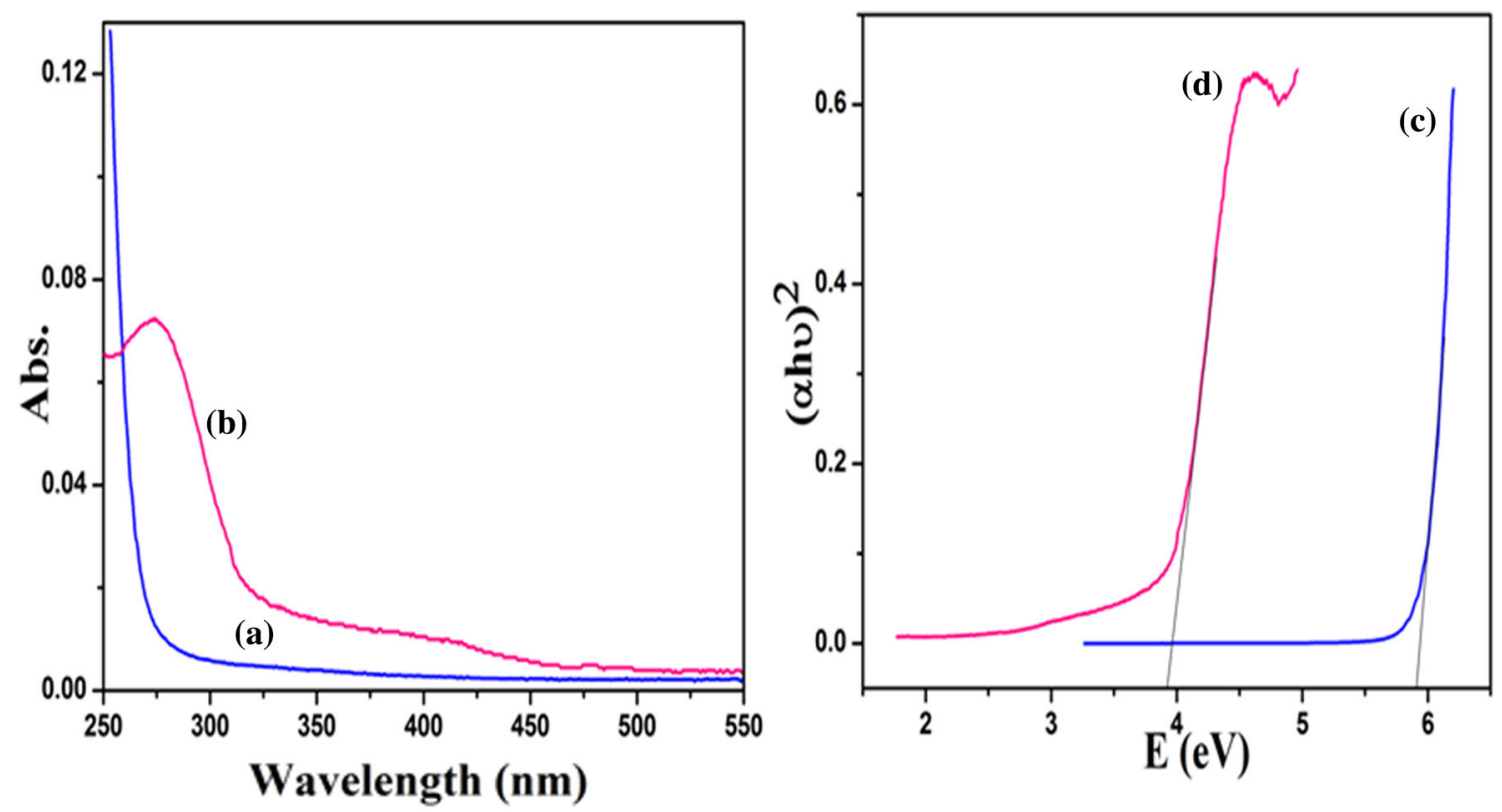

Fig. 2 UV-visible spectrum of a AC, b AC-Ni system, Tauc's plot for $\mathbf{c}$ AC and d AC-Ni system

by $T_{\text {d.w }}$. The DSC thermogram of AC-Ni system is given in Fig. S1b. The present system does not show any endothermic peak due to the $T_{\text {d.w. }}$. It means after the complex formation reaction, the chemisorbed water molecule is absent. This indicates that the hydrophobic nature of $\mathrm{AC}$ after the Ni complexation process was increased. There is no standard literature value to compare the DSC result of the present investigation.

\section{TGA profile}

The thermal stability of AC before and after complexation process was determined by TGA thermogram and the TGA thermogram of pristine AC is shown in Fig. 3a, with two step degradation process. The first minor weight loss below

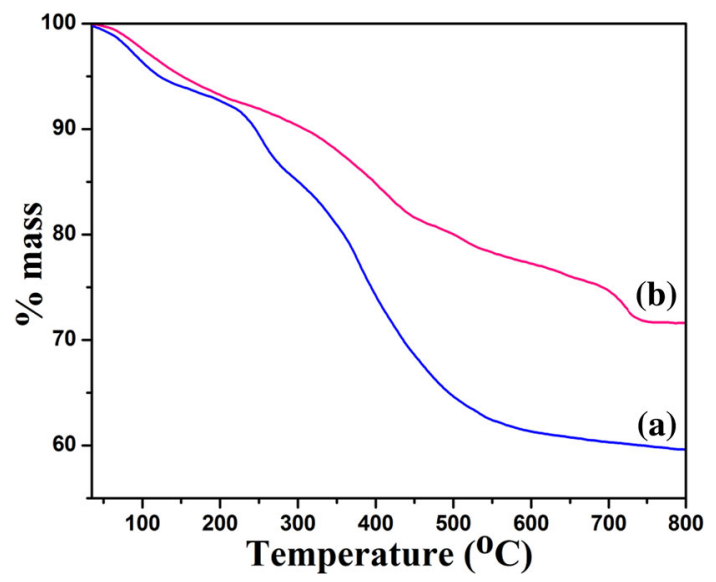

Fig. 3 TGA thermogram of a AC and b AC-Ni system
$150{ }^{\circ} \mathrm{C}$ is due to the removal of chemisorbed water molecules and moisture. $6.8 \%$ chemisorbed water molecules were present in AC. The second major weight loss around $400{ }^{\circ} \mathrm{C}$, is associated with the degradation of propylamine group (Vandarkuzhali and Radha 2013). Above $750{ }^{\circ} \mathrm{C}$ the system exhibited $60.2 \%$ as a weight residue remained. The TGA thermogram of AC-Ni system is shown in Fig. 3b with three step degradation process. The first minor weight loss below $200{ }^{\circ} \mathrm{C}$ is associated with the removal of chemisorbed water molecules and moisture. The second weight loss step at $381{ }^{\circ} \mathrm{C}$ is ascribed to the degradation of linkage between $\mathrm{Ni}$ and amino group of $\mathrm{AC}$. The third weight loss at $575{ }^{\circ} \mathrm{C}$ is due to the degradation of propylamino group of AC. Above $750{ }^{\circ} \mathrm{C}$, the system exhibits $71.8 \%$ weight as a residue. This concludes that $12.2 \%$ weight Ni nanoparticle was complexes with the AC. In comparison, the AC-Ni system exhibited improved thermal stability. It means after the complexation process the thermal stability of AC increased due to the sharing of nonbonding electrons of amino group of $\mathrm{AC}$ with the $\mathrm{Ni}^{2+}$ system. In overall comparison, the thermal stability of the AC can be increased by the complexation or by reduction reaction. In the present investigation, both complexation and reduction was carried out one by one. By the chemical reduction reaction, the central metal ion reaches its more stable octet configuration and forms the nano size. This confirmed the top-down approach of nanotechnology. By the simple chemical reduction reaction, the thermal stability of AC is increased. 


\section{XPS analysis}

XPS study was carried out to confirm the elements present in the system and to find out the outermost electronic level of Ni nanoparticle. Figure 4a represents the XPS of pristine AC. AC contains Mg2p (50.1 eV), O1s (534.8 eV), N1s (401 eV), C1s (289.1 eV) and Si2P (102.6 eV). The energy levels of O1s, N1s, C1s, Mg2p and Si2p were thoroughly discussed in the literature (Meenarathi et al. 2016). After the complexation with $\mathrm{Ni}^{2+}$, followed by the reduction reaction, confirmed the Ni nanoparticle formation by XPS. Figure $4 \mathrm{~b}$ represents the XPS of AC-Ni system. The present system also exhibited the C1S, N1S, O1S, Mg2P and Si2P. Apart from these, double peak appeared around $865 \mathrm{eV}$. The appearance of $\mathrm{Ni}_{2} \mathrm{P}_{3 / 2}(855.7 \mathrm{eV})$ and $\mathrm{Ni} 2 \mathrm{P}_{1 / 2}$ (867.9 eV) (Tao et al. 2015) confirmed the Ni nanoparticle formation. Thus, the XPS results declare that the complexation of $\mathrm{AC}$ with $\mathrm{Ni}^{2+}$ followed by the reduction leads to the formation of $\mathrm{Ni}$ nanoparticle. The outermost electronic level of Ni nanoparticle is confirmed by the XPS and co-inside with the report of Tao et al. (2015).

\section{WCA measurement}

The hydrophilic nature of $\mathrm{AC}$ before and after the complexation followed by the reduction reaction can be confirmed by WCA measurement, Fig. 5a with the contact angle of $15.6^{\circ}$. This confirmed the hydrophilic nature of pristine AC. Hence, the AC is freely soluble in water medium. The amino group of propyl group readily interacts with the water molecules. After the complexation with $\mathrm{Ni}^{2+}$, followed by reduction reaction, exhibited higher WCA $53.8^{\circ}$, Fig. 5b. This indicates that after the complexation followed by reduction, the WCA of AC increased 3.5 times. It means there was a shift from hydrophilic to

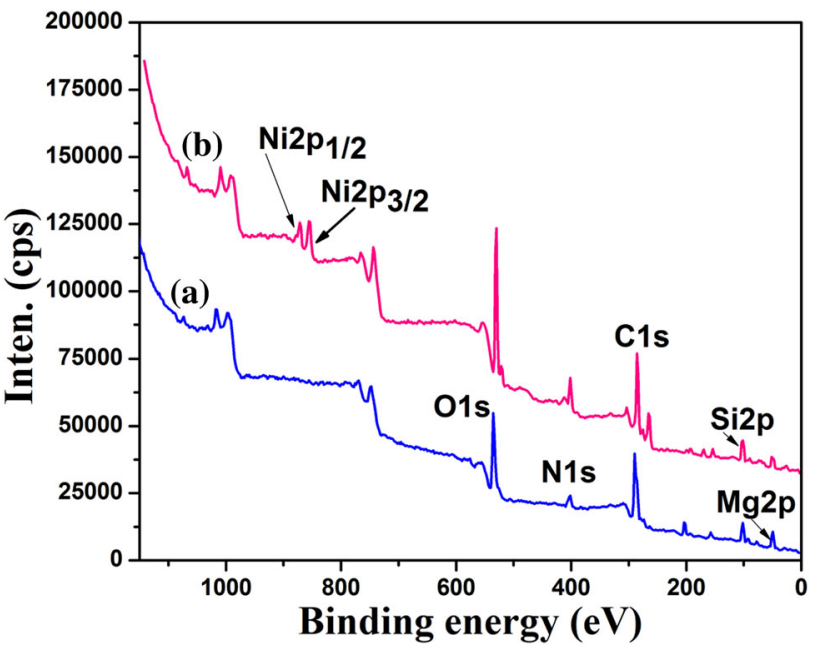

Fig. 4 XPS of a AC and b AC-Ni system hydrophobic. The increase in water contact angle leads to hydrophobic nature of AC by the complex formation with $\mathrm{Ni}^{2+}$ followed by reduction reaction. The complexation leads to the blocking and degradation of hydrogen bonding. As a result, the WCA of AC-Ni system increased. The water contact angles of metal salts modified surfaces are reported in the literature (Chen et al. 2010). The WCA of $\mathrm{Mg}$ substrate was found to be $58.4^{\circ}$ (Han et al. 2012). The WCA of Ni nanoparticle centered AC also exhibited the WCA of $53.8^{\circ}$. The increase in water contact angle supported the TGA result of $\mathrm{AC}-\mathrm{Ni}$ system.

\section{HRSEM images}

The surface morphology of AC before and after complexation with $\mathrm{Ni}^{2+}$ was analyzed by HRSEM technique. Before complexation with $\mathrm{Ni}^{2+}$ the pristine $\mathrm{AC}$ exhibits agglomerated and coarsed type morphology, Fig. S2a. After the complexation followed by reduction, the surface morphology has changed into a fiber-like morphology, Fig. S2b with coarser type morphology. The circled area confirmed the same. The breadth of the fiber varied between 0.5 and $1.2 \mu \mathrm{m}$. The HRSEM images concluded that after the complexation followed by reduction of $\mathrm{AC}$ leads to an entirely different surface morphology. The fiber-like morphology for Ni nanoparticle (Wu et al. 2015; Zhu et al. 2015) confirmed the complex formation between the amino groups of $\mathrm{AC}$ with $\mathrm{Ni}^{2+}$ ion. The further reduction reaction did not disturb the fibrous morphology of $\mathrm{AC}-\mathrm{Ni}$ system.

\section{EDX report}

The percentage of element before and after the complexation was analyzed by EDX spectrum. Figure 6a confirms the EDX spectrum of pristine $\mathrm{AC}$ with $\mathrm{C}(27.7 \%), \mathrm{O}$ (19.0\%), N (5.34\%), Si (17.08\%), $\mathrm{Cl}$ (19.52\%) and $\mathrm{Mg}$ $(10.76 \%)$ like elements. After the complexation and reduction reaction, the EDX spectrum (Fig. 6b) shows the presence of $\mathrm{C}(23.28 \%), \mathrm{O}(29.3 \%), \mathrm{Na}(16.3 \%), \mathrm{Mg}$ (4.7\%), Si (4.4\%), S (6.82\%), Cl (1.55\%) and $\mathrm{Ni}(13.94 \%)$. The $13.94 \%$ of $\mathrm{Ni}$ confirmed the complexation of $\mathrm{Ni}^{2+}$ with AC. This indicates that after the complexation followed by reduction reaction, the \% content of $\mathrm{C}, \mathrm{Mg}$ and $\mathrm{Si}$ were found to be decreased. At the same time the $\mathrm{Ni}$ content is introduced. Again this confirmed the complexation between the amino group of $\mathrm{AC}$ and $\mathrm{Ni}^{2+}$ ions.

\section{HRTEM images}

The particle size of the $\mathrm{AC}$ and its distribution were determined by HRTEM images. The HRTEM image of pristine $\mathrm{AC}$ in Fig. 7a showed an agglomerated and layer- 

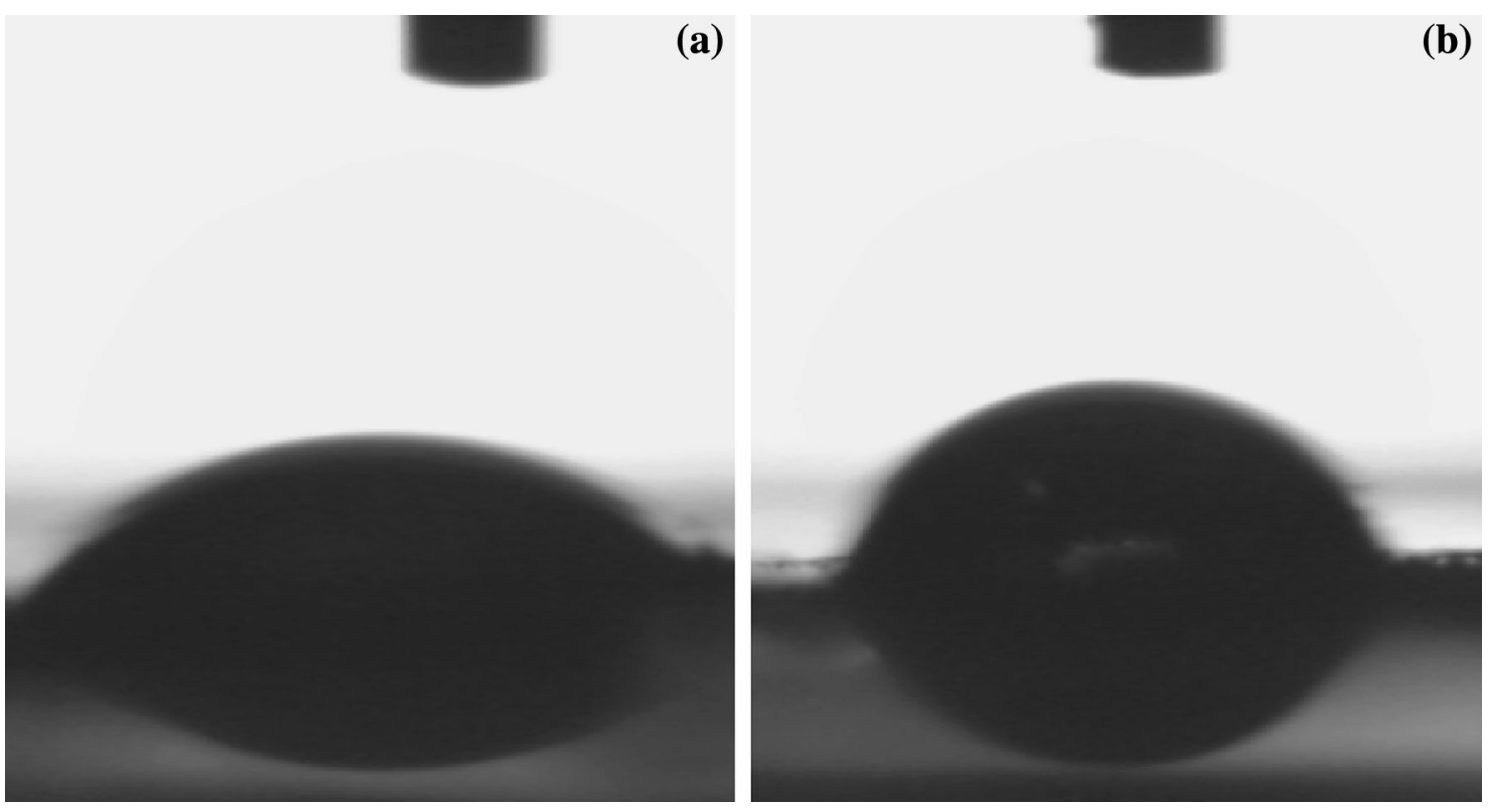

Fig. 5 WCA image of a AC and b AC-Ni system
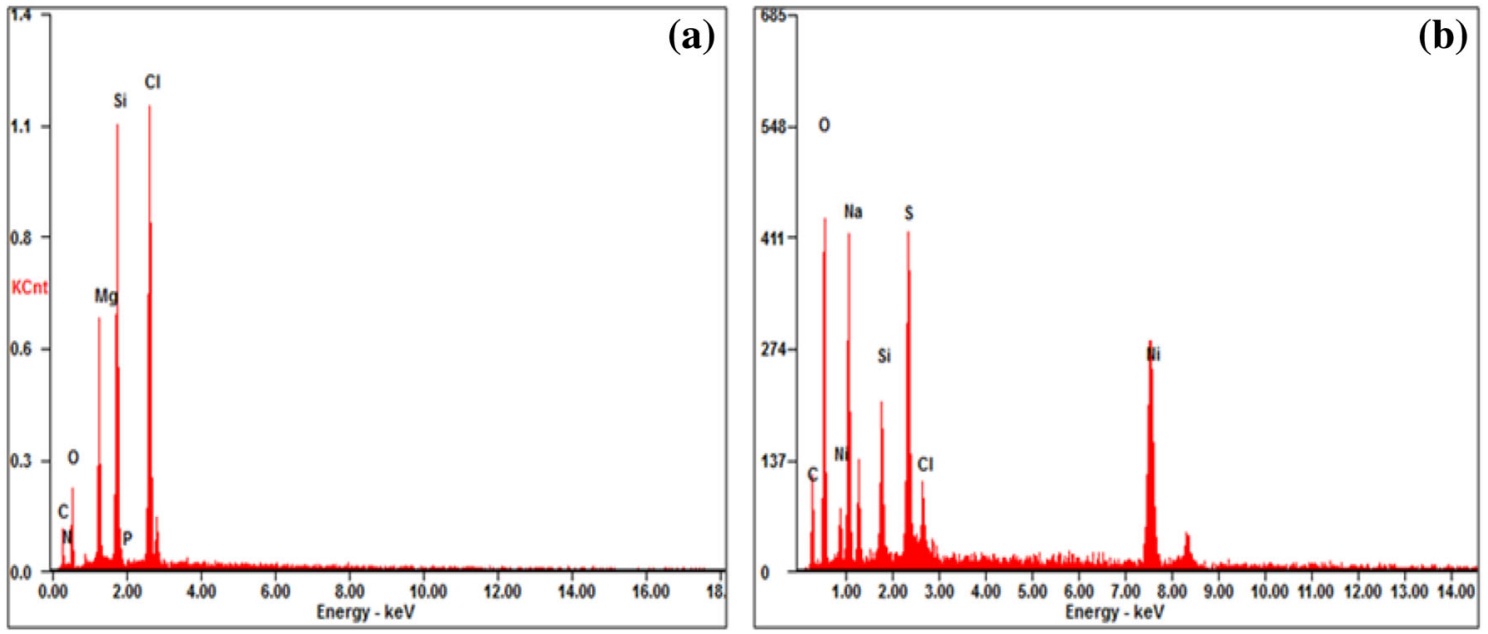

Fig. 6 EDX spectrum of a AC and b AC-Ni system

by-layer arrangement of $\mathrm{AC}$ (Chen et al. 2010). Figure 7b indicates the HRTEM image of AC-Ni system. The Ni nanoparticle with the size of less than $10 \mathrm{~nm}$ is uniformly distributed on the surface of AC (circled area). It means the amino group of $\mathrm{AC}$ is complexed with the Ni nanoparticle. The chemical conjugation of Ni nanoparticle with the AC helps for catalytic reduction purpose in the presence of a reducing agent. Moreover, during the reduction reaction the diffusion or leaching of Ni nanoparticle into the reaction medium is highly restricted. This is the novelty of the present investigation. Diffusion or leaching of $\mathrm{Ni}$ nanoparticle into the reaction medium will decrease the efficiency in the further cycles. Nevertheless, it is restricted in the present investigation. This is purely due to the complexation reaction between the amino group of $\mathrm{AC}$ and the $\mathrm{Ni}^{2+}$ ions.

\section{Catalytic activity of AC-Ni system}

The aim of the present investigation is to extend the application of Ni centered AC system to the catalysis field. $\mathrm{AC}$ is water soluble and easily separable from the reaction medium by adding ethanol. The catalysis reaction is a controllable one. The catalytic activity of AC-Ni system was tested towards the Schiff base formation reaction between PCL and ANI. Further, it was extended to the reduction of indole and $\alpha$-terpineol. 

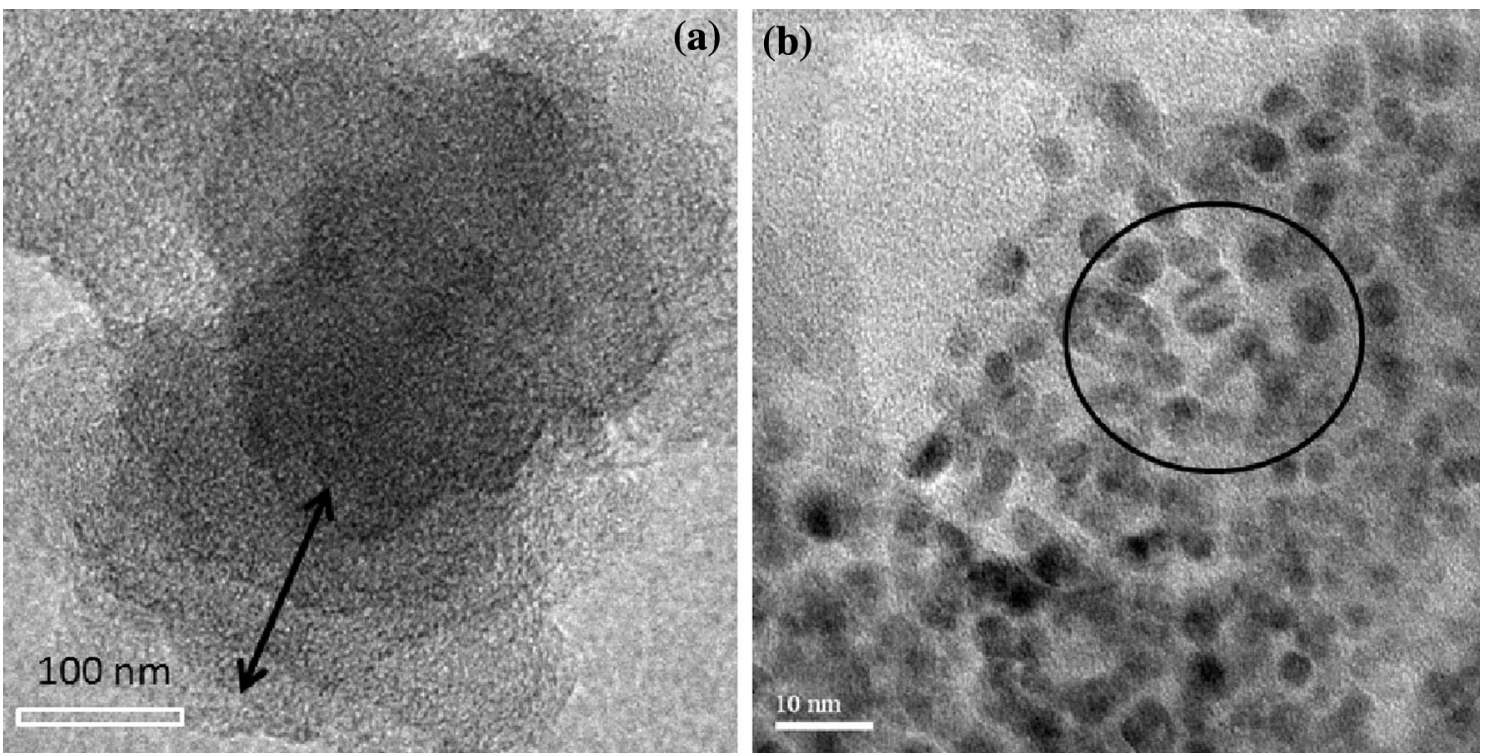

Fig. 7 HRTEM image of a AC and $\mathbf{b}$ AC-Ni system

\section{${ }^{1} H$-NMR analysis of PCL based Schiff base}

The PCL-Schiff base formation was confirmed by ${ }^{1} \mathrm{H}$ NMR spectroscopy. Figure 8a shows the ${ }^{1} \mathrm{H}-\mathrm{NMR}$ spectrum of TB end capped PCL. Here the $-\mathrm{OCH}_{2}-$ and $-\mathrm{CO}_{2}-$ $\mathrm{CH}_{2}-$ protons appeared at 4.01 and $2.7 \mathrm{ppm}$, respectively. The remaining methylene protons of PCL appeared between 1.2 and $1.7 \mathrm{ppm}$. The aromatic protons of TB appeared between 7.1 and $7.4 \mathrm{ppm}$. Figure $8 \mathrm{~b}$ denotes the ${ }^{1} \mathrm{H}-\mathrm{NMR}$ spectrum of PCL-Schiff base. Here also the above said peaks are appeared. Apart from those, one new peak appeared at $8.3 \mathrm{ppm}$ (Ibrahim et al. 2006) corresponding to the Schiff base structure. The remaining peaks matched with the structure. Here the chain ended $-\mathrm{CH}_{2}-$ $\mathrm{OH}$ group is converted into $-\mathrm{CH}=\mathrm{N}-$ like structure. By the way of Schiff base formation, one can protect the biomedically important polymer from the bacteria in air. The ${ }^{1} \mathrm{H}-\mathrm{NMR}$ spectrum confirmed the $33 \%$ formation of Schiff base between the PCL and ANI. This again confirmed the availability of free secondary - $\mathrm{OH}$ group at the chain end of PCL. This proved the catalytic activity of AC-Ni system towards the Schiff base formation.

\section{Catalytic reduction of indole}

Catalytic reduction of indole and $\alpha$-terpineol are considered to prove the catalytic activity of $\mathrm{AC}-\mathrm{Ni}$ system. The procedure is explained in the experimental part. The catalytic reduction of indole in the presence of AC-Ni catalyst system is explained here. Figure $9 \mathrm{a}-\mathrm{h}$ indicates the UVvisible spectrum of indole taken at $1 \mathrm{~min}$ time interval during the reduction reaction. The spectrum shows one absorbance peak at $339 \mathrm{~nm}$. It is very interesting to note that while increasing the reduction time the absorbance at $339 \mathrm{~nm}$ was gradually decreased. This confirmed the reduction of indole into indoline. Within $8 \mathrm{~min}, 96 \%$ of indole was reduced. To find out the $k_{\text {app }}$ value, the plot of time vs $\log \left(A / A_{0}\right)$ (Fig. 9i) was drawn. The plot was found to be decreasing trend. By drawing a linear fit, the slope and intercept values were determined as $2.85 \times 10^{-3} \mathrm{~s}^{-1}$ and $0.20 \mathrm{~s}$, respectively. This shows that within $0.20 \mathrm{~s}$ the reduction of indole started on the surface of AC-Ni catalyst. Gribble (1998) reported the reduction of indole in an acidic medium produced the maximum yield of $69 \%$ with simultaneous alkylation. In the present investigation, $96 \%$ yield within $8 \mathrm{~min}$ and without alkylation was produced. When compared with literature the present system produced an excellent result (i.e.) high \% yield within short period of time and without alkylation. This confirmed the catalytic activity of AC-Ni system towards the reduction of indole with high $\%$ yield.

\section{Catalytic reduction of $\alpha$-terpineol}

Catalytic reduction of $\alpha$-terpineol was carried out under identical experimental conditions as mentioned above. The UV-visible spectrum was recorded at 1 min time interval (Fig. 10a-i). The spectrum shows two peaks at 279 and $333 \mathrm{~nm}$ corresponding to $\pi$ to $\pi^{*}$ and $n$ to $\pi^{*}$ transitions, respectively. While increasing reduction time, the absorbance at 279 and $333 \mathrm{~nm}$ were gradually decreased. This confirmed the reduction of $\alpha$-terpineol into 1-isopropyl-4methyl cyclohexane. This is proposed based on the literature. It means both the $\mathrm{C}=\mathrm{C}$ and $\mathrm{C}-\mathrm{OH}$ were reduced simultaneously. It is very surprise to note that the tertiary alcoholic group was reduced in the presence of $\mathrm{AC}-\mathrm{Ni}$ 
Fig. $8{ }^{1} \mathrm{H}-\mathrm{NMR}$ spectrum of a TB end capped PCL and b PCL-Schiff base
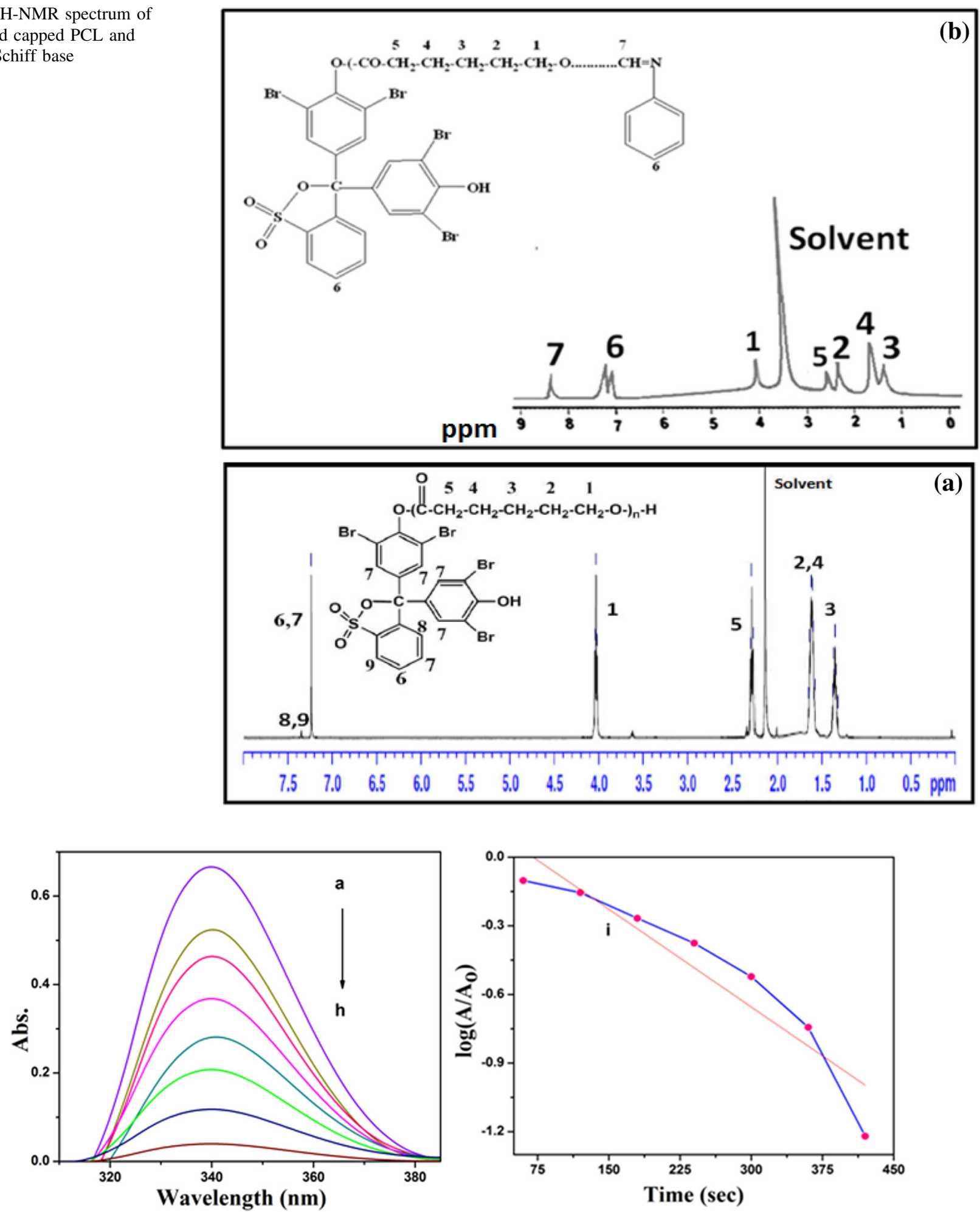

Fig. 9 UV-visible spectrum of Indole $\mathbf{a}-\mathbf{h}$ taken at $1 \mathrm{~min}$ time interval in the presence of AC-Ni system and $\mathbf{i}$ the plot of time vs $\log \left(A / A_{0}\right)$

system. Yasuda et al. (2001) reported the catalytic reduction of tertiary alcoholic group into alkane. Based on the literature, it is proposed that the $\mathrm{C}=\mathrm{C}$ and $\mathrm{C}-\mathrm{OH}$ group was reduced in the presence of $\mathrm{AC}-\mathrm{Ni}$ catalyst system. The rate of reduction of $\mathrm{C}=\mathrm{C}$ and $\mathrm{C}-\mathrm{OH}$ were compared by determining the $k_{\text {app }}$ values. To find out the $k_{\text {app }}$ values, the plots of time Vs $\log \left(A / A_{0}\right)$ (Fig. 10j, for $279 \mathrm{~nm}$ and Fig. 10k, for $333 \mathrm{~nm}$ ) were drawn. Both the plots were found to be 

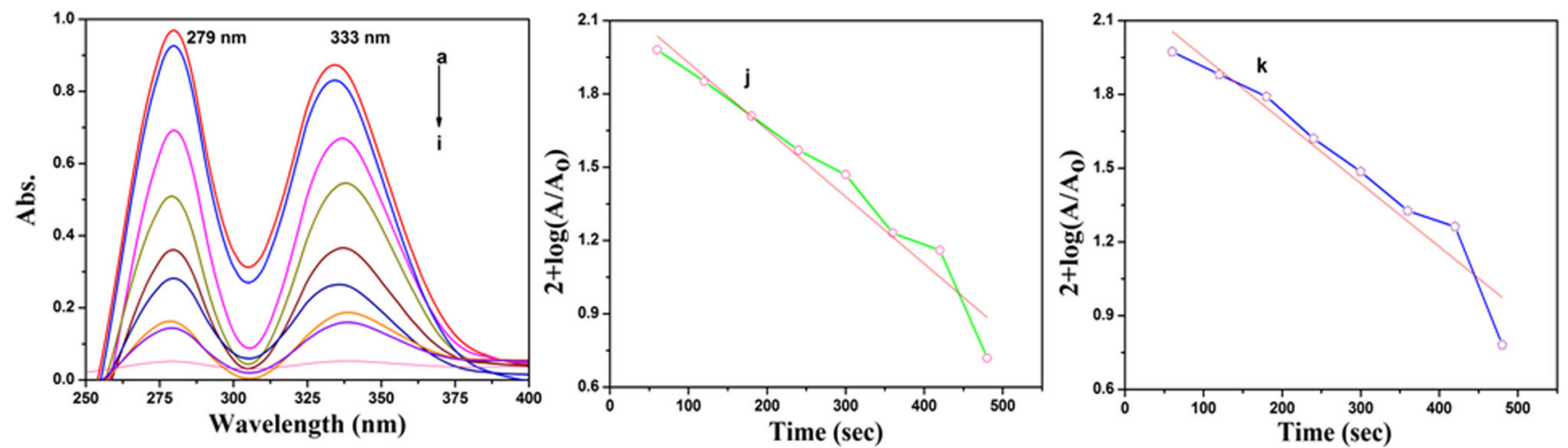

Fig. $10 \mathrm{UV}$-visible spectrum of $\alpha$-terpineol $\mathbf{a}-\mathbf{i}$ taken at 1 min time interval in the presence of AC-Ni system. The plot of $\mathbf{j}$ time vs $\log \left(A / A_{0}\right)$ for a peak at $279 \mathrm{~nm}$ and the plot of $\mathbf{k}$ time vs $\log \left(A / A_{0}\right)$ for a peak at $333 \mathrm{~nm}$

decreasing trend. From the slope value, the $k_{\text {app }}$ values were determined. The intercept value informs the induction time value. For the reduction of $\mathrm{C}=\mathrm{C}$, the $k_{\text {app }}$ and $\mathrm{Ti}$ values were determined as $2.74 \times 10^{-3} \mathrm{~s}^{-1}$ and $2.20 \mathrm{~s}$, respectively. For the reduction of $\mathrm{C}-\mathrm{OH}$, the $k_{\text {app }}$ and $\mathrm{Ti}$ values were determined as $2.57 \times 10^{-3} \mathrm{~s}^{-1}$ and $2.21 \mathrm{~s}$, respectively. In comparison, the $\mathrm{C}=\mathrm{C}$ reduction rate was slightly high. This is due to the catalytic activity of AC-Ni system. Their $\mathrm{Ti}$ values are almost equal. It means at equal $\mathrm{Ti}$ value, it produced different $k_{\text {app }}$ value. This proved the catalytic activity of AC-Ni system towards the reduction of $\alpha$-terpineol. The $k_{\text {app }}$ value for the catalytic reduction of $\alpha$ terpineol is not reported in the literature and hence it is very difficult to compare our results with the literature report. So that the results are compared internally.

\section{Conclusions}

From the above study the niche points are presented here as conclusion. The appearance of metal nitrogen stretching $\left(661 \mathrm{~cm}^{-1}\right)$, shifting in the peak position and disappearance of free amino group stretching around $3100 \mathrm{~cm}^{-1}$ confirmed the complex formation between the $\mathrm{Ni}$ nanoparticle and amino group of AC. The decrease in band gap energy $(3.96 \mathrm{eV})$ confirmed the complex formation between the Ni nanoparticle and amino group of AC. The disappearance of $T_{\text {d.w }}$ around $150{ }^{\circ} \mathrm{C}$ in the DSC indicated the absence of chemisorbed water molecules in the $\mathrm{AC}-\mathrm{Ni}$ system and co-supported by the increase in contact angle by the WCA measurement. The increase in thermal stability above $750{ }^{\circ} \mathrm{C}$ declared the complex formation between Ni nanoparticle and AC. The XPS study indicated the presence of $\mathrm{Ni}_{2} \mathrm{P}_{1 / 2}$ and $\mathrm{Ni}_{2} \mathrm{P}_{3 / 2}$ around $850 \mathrm{eV}$ declared the formation of Ni nanoparticles. The HRSEM image exhibited the fibrous morphology rather than the spherical morphology of AC-Ni system. The HRTEM images confirmed the formation of $\mathrm{Ni}$ nanoparticles with the size of $<10 \mathrm{~nm}$. Appearance of a peak at $8.3 \mathrm{ppm}$ in ${ }^{1} \mathrm{H}-\mathrm{NMR}$ spectrum confirmed the Schiff base formation. The $k_{\text {app }}$ value for the indole system was calculated as $2.85 \times 10^{-3} \mathrm{~s}^{-1}$. The catalytic reduction of $\alpha$-terpineol indicated that the $k_{\text {app }}$ value for the reduction of $\mathrm{C}=\mathrm{C}$ is greater than the $k_{\text {app }}$ value of $\mathrm{C}-\mathrm{OH}$.

Acknowledgements I express my sincere thanks to Prof. Dr. M. Eswaramoorthy (my second GURU), MCPU, Nanomaterials and Catalysis Lab, JNCASR, Bangalore, India for his valuable suggestion and help. Dr. N. Sundararajan, Associate Professor, Department of English, KCET is gratefully acknowledged for his valuable help during the preparation of this manuscript.

\section{Compliance with ethical standards}

Conflict of interest The authors declare that they have no conflict of interest.

Open Access This article is distributed under the terms of the Creative Commons Attribution 4.0 International License (http:// creativecommons.org/licenses/by/4.0/), which permits unrestricted use, distribution, and reproduction in any medium, provided you give appropriate credit to the original author(s) and the source, provide a link to the Creative Commons license, and indicate if changes were made.

\section{References}

Alcanter NA, Aydil ES, Israelchvili JN (2000) PEG coated biocomponent surfaces. J Biomed Mater Res 5:343-351

Arvaniti OS, Hwang Y, Andersen HR, Stasinalas AS, Thomaidis NS, Aloupi M (2015) Reductive degradation of perflourinated compounds in water using Mg-aminoclay coated nanoscale zero valant iron. Chem Eng J 262:133-139

Ayyala V, Corma A, Iglesias M, Rincon JA, Sanchez F (2004) Hybrid organic inorganic catalyst: a co-operative effect between support and Pd and nickel sal-complexes on catalytic hydrogenation of amines. J Catal 224:170-177

Behal A (1910) Nickel catalyzed reduction of terpineol. Comptes Rendus 150:1762-1765

Biswas KM, Jackson AH (1968) Diborane as a reducing agent-II. The reduction of indole and pyrrole carbonyl derivatives. Tedrahedron 24:1145-1162 
Burkett S, Press A, Mann S (1997) Synthesis, characterization and reactivity of layered inorganic nanocomposites based on trioctahedral phyllosilicates. Chem Mater 9:1071-1073

Celebi M, Yurdesi M, Bulut A, Kaya M, Zahmakiran M (2016) Palladium nanoparticle supported on amine functionalized $\mathrm{SiO}_{2}$ for the catalytic hexavalant chromium reduction. Appl Catal B Enviorn 180:53-64

Chen HH, Anbarasan R, Kuo LS, Chen PH, Chiang KF (2010) Synthesis, characterizations and hydrophobicity of micro/nano scaled heptadecafluorononanoic acid decorated copper nanoparticle. Nano Micro Lett 2:101-105

Cui W, Zhu H, Jia M, Ao W, Zhang Y, Zhaorigetu B (2013) One pot synthesis of imines from benzyl alcohol and amines on $\mathrm{Au} / \mathrm{ZrO}_{2}$ catalyst. React Kinet Mech Catal 109:551-562

Datta KKR, Eswaramoorthi M, Rao CNR (2007) Water solubilized aminoclay metal nanoparticle composites and their novel properties. J Mater Chem 17:613-615

Datta KKR, Achari A, Eswaramoorthi M (2013) Aminoclay: a functional layered material with multifaceted applications. J Mater Chem A 2:6707-6719

Deng DS, Han GW, Zhu X, Xu X, Gong YT, Wang Y (2015) Selective hydrogenation of unprotected indole to indoline over $\mathrm{N}$ doped carbon supported $\mathrm{Pd} / \mathrm{C}$ catalyst. Chin Chem Lett 26:277-281

Duraimurugan K, Radhika S, Baskaran I, Anbarasan R (2008) Clay catalyzed synthesis of poly(glycolicacid). Chin J Polym Sci 26:393-398

Franquin D, Monteverdi S, Molina S, Bettahar MM, Fort Y (1999) Colloidal nanometric particles of $\mathrm{Ni}$ deposited on $\gamma$-alumina: characteristics and catalytic properties. J Mater Sci 34:4481-4488

Geng L, Song J, Zheng B, Wu S, Zhang W, Jia M, Liu G (2016) Aerobic oxidative coupling of alcohols and amines to imines over iron catalyst supported on mesoporous carbon. Chin J Catal 37:1451-1460

Giardono NAG, Zhenyu TDE, Yacob BS, Yang CC, Notestein JM (2016) Silica support modifications to enhance Pd catalyzed deoxygenation of stearic acid. Appl Catal B Environ 192:93-100

Gribble GW (1998) Sodium borohydride in carboxylicacid media: a phenomenal reductionystem. Chem Soc Rev 27:395-404

Haldoraj Y, Rengaraj A, Ryu T, Shin J, Huh YS, Han YK (2015) Response surface methodology for the optimization of lanthanum removal from an aqueous solution using a $\mathrm{Fe}_{3} \mathrm{O}_{4} /$ chitosan nanocomposite. Mater Sci Eng B 195:20-29

Han M, Go S, Ahn Y (2012) Fabrication of superhydrophobic surface on magnesium substrate by chemical etching. Bull Korean Chem Soc 33:1363-1366

Hwang Y, Lee YC, Mines PD, Huh YS, Anderson HR (2014) Nanoscale zero valent iron synthesizing $\mathrm{Mg}$-aminoclay solution exhibits increased stability and reactivity for reductive decontamination. Appl Catal B Environ 147:748-755

Ibrahim MN, Hamad KJ, Jorosh SH (2006) Synthesis and characterization of some Schiff bases. Asian J Chem 18:2404-2406

Jeyapriya M, Meenarathi B, Anbarasan R (2016) Synthesis, characterization, catalytic and splinting activity of nano Ag end capped L-glutathione bridged amphiphilic diblock copolymer. J Appl Polym Sci 133:1-11

Kang KS, Lee HU, Kim MI, Park SY, Chang SJ, Lee YC, Park HG (2015) Invitro cytotoxicity assessment of carbon nanodot conjugated Fe-aminoclay and its bio-imaging applications. J Nanobiotechnol 13:88-107

Kulkarni A, Zhou W, Torok B (2011) Heterogeneous catalytic hydrogenation of unprotected indoles in water. A green solution to a long standing challenge. Org Lett 13:5124-5127

Kuwano R, Kashiwabara M, Sato K, Ito T (2006) Catalytic asymmetric hydrogenation of indole using a rhodamine complex with a chital bisphosphine ligand PhTRAP. Tedrahed Asymmetry $17: 521-535$

Kwon MS, Kim S, Park S, Bosco W, Chidrala RK, Park J (2009) One pot synthesis of imines of secondary amines by Pd catalyzed coupling of benzyl alcohols and primary amines. J Org Chem 74:2877-2879

Lee YC, Chang SJ, Choi MH, Jeon TJ, Ryu T, Huh YS (2013) Self assembled graphene oxide with organo building blocks of $\mathrm{Fe}-$ $\mathrm{AC}$ for heterogeneous lite reaction at near buetnal $\mathrm{pH}$ : a batch experiment. Appl Catal B Environ 142-143:494-503

Lee YC, Lee K, Hwang H, Anderson HR, Lee SY, Choi MH, Huh YS (2014) Aminoclay templated nanoscale zero valant iron synthesis for efficient harvesting of oleagigous microalga, chlorella ep. K.R.1. RSC Adv 4:4122-4128

Lee JY, Choi S, Lee HU, Lee YC (2015) Fe-aminoclay entrapping electro spun nanofibers for environmental engineering applications. Korean J Chem Eng 32:1727-1732

Leete E, Marion L (1953) The hydrogenolysis of 3-hydroxy methylindole and other indole derivatives with Lithium aluminiumhydride. Can J Chem 31:775-784

Li J, Kao WJ (2003) Synthesis of polyethylenelglycol derivatives and PEGylated peptide biopolymer conjugate. Biomacromolecules 4:1055-1067

Liu D, Ren S, Wang G, Wen L, Yu J (2009) Rapid synthesis and morphology control of nickel powders via a microwave assisted chemical reduction method. J Mater Sci 44:108-113

Liu X, Xiao J, Zhong W, Xu Q, Su S, Yin D (2016) Catalytic aerobic oxidation of 5-hydroxy methyl ferfusal over $\mathrm{VO}^{2+}$ and $\mathrm{Cu}^{2+}$ immobilized on amino funtionalised SBA-15. Chem Eng J 283:1315-1321

Maggi A, Madsen R (2012) Dehydrogenative synthesis of imines from alcohols and amines catalyzed by a Ruthenium $N$ heterocyclic carbene complex. Organometallics 31:451-455

Meenarathi B, Siva P, Palanikumar S, Kannammal L, Anbarasan R (2016) Synthesis, characterization and drug release activity of poly(caproalctone) $/ \mathrm{Fe}_{3} \mathrm{O}_{4}$-alizarinred nanocomposites. Nanocomposites 2:98-107

Patil AJ, Eswaramoorthi M, Mann S (2004) Synthesis and self assembly of organoclay wrapped biomolecules. Angew Chem Int Ed 43:4928-4933

Ramya R, Jaculin A, Raiza S, Devi R, Pandian K (2015) Synthesis of aminoclay protected Palladium nanoparticles and study its catalytic activity in organic synthesis. Int J Chem Technol Res 7:1297-1302

Ravula S, Essner JB, Ala W, Parada LP, Kargupta R, Hull GJ, Sengupta S, Baker GA (2015) Sunlight assisted route to anti plasmaotri aminoclay catalysts. Nanoscale 7:86-91

Rosetto E, Nicola BP, De Souza RF, Gusmao KB, Pergher C (2015) Heterogeneous complexes of nickel metal with $\beta$-diimine applications in olefin oligomerization. J Catal 323:45-54

Sindhuja E, Ramesh R (2014) Direct synthesis of imines from primary alcohols and amines using an active ruthenium(II) $N, N, N$-pincer complex. Tedrahed Lett 55:5504-5507

Suresh K, Vinothkumar R, Kumar M, Jeyapriya M, Anbarasan R, Pugazhlendhi G (2017) Sonication assisted synthesis of poly(styrene)/organoclay nanocomposites: influence of clay content. Appl Nanosci 7:215-223

Tamura M, Tomishige K (2014) Redox properties of $\mathrm{CeO}_{2}$ at low temperature: the direct synthesis of imines from alcohols and amines. Angew Chem Int Ed 53:1-5

Tao XJ, Li ZW, Chen HJ, Zhang PJ, Zhang ZJ, Wu ZS, Dang HX (2015) A new approach to synthesize nickel nanoparticles. Acta Phys Chim Sin 21:569-572

Vandarkuzhali SAA, Radha N (2013) Water soluble aminoclay for catalytic reduction of p-nitrophenol. Orient J Chem 29:661-667

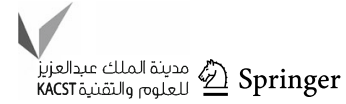


von Rudloff E (1963) Gas liquid chromatography of terpenes. Can J Chem 41:1-8

Wallach O (1911) Catalytic reduction of terpineol by Palladium. Ann 381:55-58

Wang L, Chen B, Ren L, Zhang H, Lu Y, Gao S (2015) Vanadium catalyzed direct synthesis of imines from amines or alcohol and amines by an aerobic oxidative reaction under mild conditions. Chin J Catal 36:19-23

Wang L, Duan L, Ramambre B, Das B, Thapper A, Diner P, Sun L (2016) A Nickel (II) Pd complexation and electrocatalyst for water oxidation. J Catal 355:72-75

Wu JH, Liu G, Su T, Zhang WH, Luo MM, Wei T (2015) Preparation of fibrous nickel powder by precipitation transformation coupled with thermal decomposition. Trans Nonferrous Met Soc Chin 25:2653-2660

Yang L, Choi SK, Shin HJ, Han HK (2013) 3-aminopropyl functionalized magnesium phyllosilicate as an organoclay based drug carrier for improving the bioavailability of flurbiprofen. Int J Nanomed 8:4147-4155

Yang L, Lee YC, Kim MI, Huh YS, Shao Y, Han HY (2014) Biodistribution and clearance of aminoclay nanoparticles: implication for in vivo applicability as a tailor-made drug delivery carrier. J Mater Chem 2:7567-7573
Yasuda M, Onishi Y, Ueba M, Baba A (2001) Direct reduction of alcohols: highly chemoselective reducing system for secondary and tertiary alcohols using chlorodiphenylsilane with catalytic amount of Indium trichloride. J Org Chem 66:7741-7744

Zhang G, Hanson SK (2013) Cobalt catalyzed acceptorless alcohol dehydrogenation: synthesis of imines from alcohols and amines. Org Lett 15:650-653

Zhang E, Tian H, Xu S, Yu X, Xu Q (2013) Iron catalyzed direct synthesis of imines from amines or alcohols and amines via aerobic oxidative reactions under air. Org Lett 15:2704-2707

Zhu K, Wang D, Liu J (2001) Self assembled materials for catalysis. Nano Res 2:21-29

Zhu SW, Jing MX, Ti ZC, Chen LL, Shen XQ (2015) Effects of fibrous Nickel additives on the electrochemical properties of $\mathrm{LiFePO}_{4}$ cathode for Lithium-ion battery. Int J Electrochem Sci 10:10597-10606

\section{Publisher's Note}

Springer Nature remains neutral with regard to jurisdictional claims in published maps and institutional affiliations. 